\title{
Comparison of Machining Temperature in High Speed Grinding of Metallic Materials and Brittle Materials
}

\author{
Chongjun $\mathrm{Wu}^{1}{ }^{1, a}$, Beizhi $\mathrm{Li}^{1}$, Jianguo $\mathrm{Yang}^{1}$ and Steven $\mathrm{Y}$. Liang ${ }^{2}$ \\ ${ }^{1}$ Donghua University, Shanghai, China \\ ${ }^{2}$ Georgia Institute of Technology, Atlanta, USA
}

\begin{abstract}
Grinding has always been a high energy expenditure process, which generally produce massive grinding heat and possibly produce thermal damage in workpiece ground surface. Therefore, a good understanding of grinding temperature characteristics is important to lower the thermal effect on the workpiece quality. However, the grinding temperature characteristic differs when grinding of different materials, especially for those hard-to-machine materials (eg. Titanium alloys and ceramics). Therefore, this paper is devoted to investigate different grinding temperature characteristics for metallic materials and brittle materials. In order to detect the grinding temperature, a grindable thermocouple technique with NI-DAQ device is adopted in diamond wheel grinding of ceramics and CBN grinding of Titanium alloys. The results show that the temperature characteristics for ceramics is totally different with Titanium alloys. When the grinding wheel speed increases, the grinding temperature increases all the way when grinding of Titanium alloys. However, there is a temperature turning point for grinding of ceramics. When the wheel speed surpasses the turning point, the grinding temperature goes down and closes at a relatively low temperature.
\end{abstract}

\section{Introduction}

Grinding has been widely used as a precision machining method in various engineering application, such as aerospace, automobile and machinery industry [1-2]. However, grinding is also a complex machining process with dynamic active number, random grit topology and cutting angle. The interactive abrasive grits have typical negative rake angle [3], which will cause a high degree of material deformation and thus produce voluminous grinding heat and unpleasant residual stress [4]. Moreover, the grinding induced temperature is obviously different when machining different materials. It has been proven that a thermal shock condition of temperature $600-1500 \mathrm{k}$ and pressure 5-25 GPa for Silicon Carbide ( $\mathrm{SiC}$ ) will bring about a phase transition [5] and strength reduction [6]. While for the metallic materials, the ground surface is easy to get burnt to worsen the desired quality [7]. Therefore, a good understanding of grinding temperature for different materials would be helpful to minimize the thermal effect on grinding quality.

\footnotetext{
${ }^{a}$ Corresponding author:wcjunm@126.com
} 
The high speed grinding process has been regarded as a high efficient method in precision machining of hard-to-machine materials. It is generally characterized by an increase of wheel velocity above $60 \mathrm{~m} / \mathrm{s}$, which will substantially reduce the maximum undeformed chip thickness compared with conventional grinding of below $40 \mathrm{~m} / \mathrm{s}$ [8]. High speed machining was first proposed by German engineer Dr. Carl Salomon in the year 1931[9]. Based on some experiments, it was assumed that the grinding surface temperature will first increase with the increase of machining speed in high speed machining and then falls down after a turning point However, there is no consistent result on this assumption [10-13]. This is because that different machining methods and materials may cause different temperature characteristics. In recent years, lots of work has been done to investigate the grinding temperature. Thermocouples have been widely as a reliable temperature detecting method to obtain the machining temperature [14-16]. Based on grindable thermocouples, researchers have done experiments on high speed grinding of metallic materials [17-18] and brittle materials [13]. It was found that the temperature characteristics are totally different. Therefore, to understand grinding temperature of different materials, more efforts are still needed to be done.

This paper is intended to investigate different temperature characteristics when grinding different materials. The typical brittle materials ceramics and metallic material Titanium alloys will be used in this paper. High speed grinding experiments are conducted on both of these materials to detect the machining induced temperatures. Then a comparison of the process parameters on grinding temperature will be fully discussed.

\section{Experiments}

The grinding experiments are conducted on a high speed cylindrical grinder MGKS1332/H CNC from Shanghai Machine Tool Works Ltd. This grinder can reach up to a rotational speed up of $8000 \mathrm{rpm}$ or linear velocity $160 \mathrm{~m} / \mathrm{s}$. The workpiece specimens used in this paper are reaction-sintered $\mathrm{SiC}$ and Titanium Alloys. A vitrified diamond grinding wheel, model D91 V+2046J1SC C150 E, was used for $\mathrm{SiC}$ grinding. Another vitrified CBN grinding wheel, model CBN B91V175, was used for TC4 (Ti$6 \mathrm{Al}-4 \mathrm{~V})$ grinding. Two of these grinding wheels have a width of $22 \mathrm{~mm}$ and diameter of $400 \mathrm{~mm}$. The experiments setup was given in the Fig. 1(TC4 as example). It can be found that a NIUSB-9213 was connected with a computer to detect the grinding temperature. The grindable embedded thermocouple was installed into the workpiece to detect the real time grinding temperature.

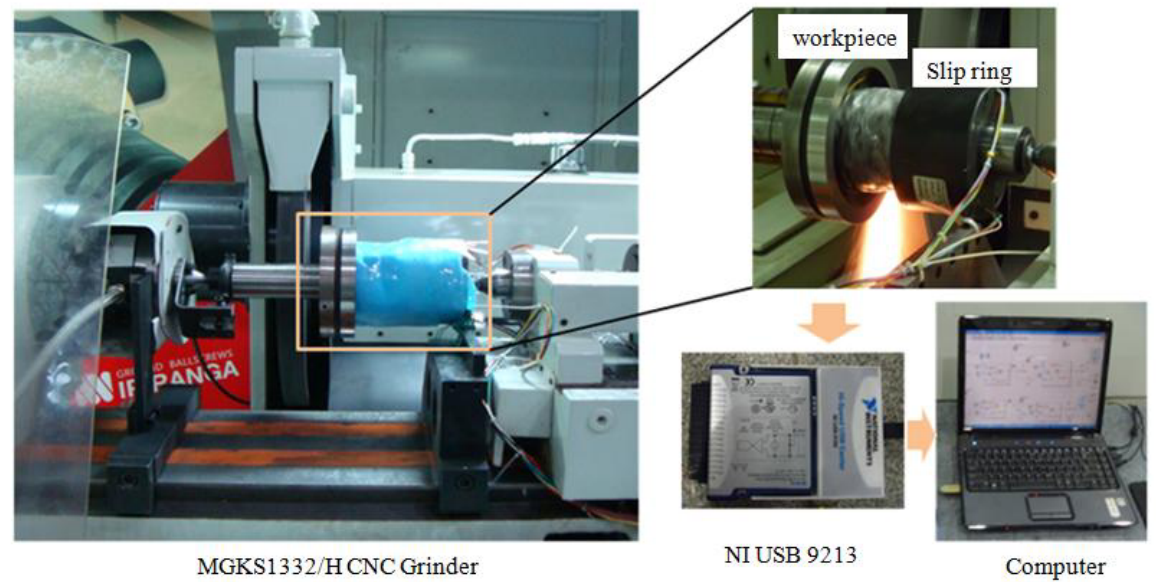

Figure1. Temperature experiments setup

\section{Results and Discussion}




\subsection{Speed effect on grinding temperature}

In high speed grinding process, the increased grinding velocity will greatly reduce the undeformed chip thickness and thus a reduction of grinding force. However, increase of grinding wheel velocity will cause a substantial increase of grinding power, which will produce more heat. The consumed grinding power can be expressed as:

$$
P=F_{t} \cdot V_{s}
$$

where $P$ is the grinding power, $F_{t}$ is the tangential force and $V_{s}$ is the wheel liner speed. As the increase of wheel speed is higher than the reduction of tangential grinding force, thus the grinding power needed to remove a certain amount of material will increase. Thus, more heat will be produced and the grinding surface temperature is expected to increase with the increase of machining speed. However, it may not be the same in high speed grinding process. In a higher speed grinding process, the faster the machining is, the less time there will be for the heat to be absorbed by the workpiece. Moreover, the grinding chips can be helpful in taking away the produced heat. In high speed grinding, the heat can be taken away before a new chip was generated[19]. Therefore, the mechanics of grinding temperature is complicated in high speed grinding process.
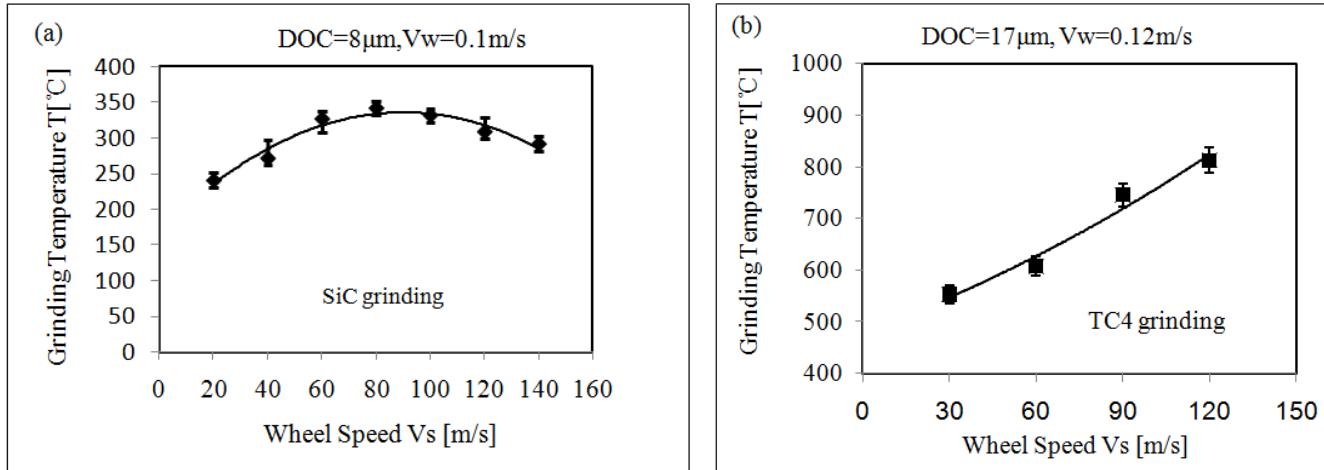

Figure 2. Speed effect on grinding temperature

Grinding experiments on $\mathrm{SiC}$ and $\mathrm{TC} 4$ was developed on a high speed grinding machine to study the actual features in grinding processes. Fig. 2 shows that grinding temperature trend under an elevation of grinding wheel speed while keeping the worktable speed and depth of cut constant. In this paper, the error bar gives the error of 10 groups of temperature data. Moreover, the solid curve was fitted by binomial model. It can be found that the temperature does not increase all the way as predicted. The temperature value for $\mathrm{SiC}$ is much lower than TC4. From the Fig. 2 (a), the grinding temperature of $\mathrm{SiC}$ first rises when the wheel speed is below $80 \mathrm{~m} / \mathrm{s}$, then it goes down. However, the grinding temperature rises up all the way with the increase of grinding wheel speed (Fig. 2(b)). Therefore, it can be found that more heat was accumulated in TC4 grinding than SiC grinding. One is because of the heat dissipation for TC4 that is much slower than the SiC. The heat conductivity for $\mathrm{SiC}$ is about $83.6 \mathrm{~W} /(\mathrm{m} . \mathrm{K})$ compared with $6.8 \mathrm{~W} /(\mathrm{m} . \mathrm{K})$ for $\mathrm{TC} 4$, which means that the heat dissipation of $\mathrm{SiC}$ is 12 times faster than TC4. The other factor is more plastic deformation in TC4 grinding. As typical metallic materials, the TC4 can allow a higher elastic and plastic deformation, which is the main stage to produce machining heat. However, as the typical hard and brittle materials, $\mathrm{SiC}$ have a elastic modulus of more than 3 times of TC4, much stronger deformation resistance than TC4. That's why the grinding of $\mathrm{SiC}$ is much easier to lead a lower temperature and a shift of temperature trend.

In order to analyze the cooling efficiency in temperature effect on $\mathrm{SiC}$, the grinding data was given in Fig. 3. In the Fig. 3, the comparison result of dry and wet grinding under 5\% water-soluble metal cutting fluid was depicted. It can be found that the wet grinding helps to reduce the grinding temperature and it is just about $70 \%$ of the the dry grinding temperature. Moreover, the wet grinding shows the same temperature trend with the dry grinding in high speed grinding process. 


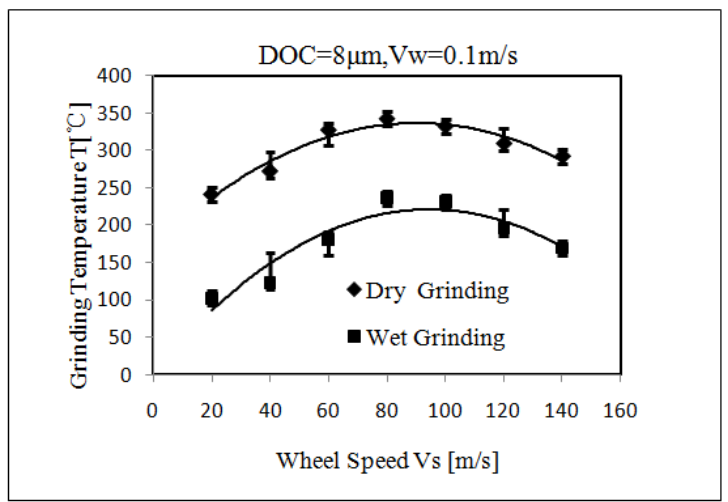

Figure 3. Cooling effect on grinding temperature

\subsection{High speed efficient grinding under a lower temperature}

Machining induced temperature is always one of the most significant factors that affect the machined surface quality. The material removal rate is a parameter to assess the machining economical efficiency. It can be defined as:

$$
Q^{\prime}{ }_{w}=V_{w} \cdot a_{e}
$$

where $Q^{\prime}{ }_{w}$ is the material removal rate, $a_{e}$ is the depth of cut (DOC) and $V_{w}$ is the worktable speed. The combined increase of depth of cut and worktable speed is always the main method to help increase the material removal volume. Fig. 4 gives the typical temperature trend when the wheel speed and depth of cut keep constant. From the Fig. 4 (a), it can be found that the temperature of SiC does not increase with the increase of worktable speed. However, the temperature for TC4 drops down when the worktable speed increases. The increase of worktable speed will lift the workpiece rotational speed, which will not only help to reduce the cutting time for a single grit, also improve the heat transfer rate into the air. Therefore, the increase of worktable speed is different from the increase of depth of cut, which has been proved to lead a liner increase of grinding temperature when increased [13]. Thus, in order to abtain a higher material removal volume, the increase of workpiece rotational speed will be more helpful in suppressing the grinding temperature.
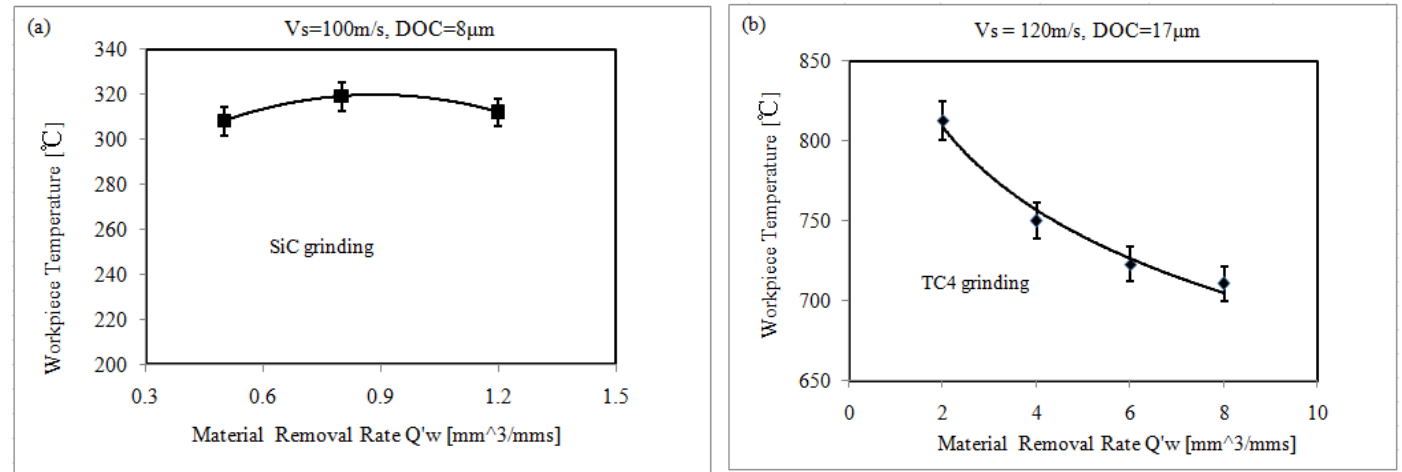

Figure4. Workpiece rotational speed's effect on temperature

In order to lower the grinding temperature, a fast shallow plunge grinding tests are deployed. The results for $\mathrm{SiC}$ and $\mathrm{TC} 4$ are given in the below Fig. 5. In the experiments, the material removal rate and wheel speed were set to be a constant. It can be seen from the data that the fast shallow plunge grinding will help substantially reduce the grinding temperature. Thus, in order to keep a stable material removal rate, a joint of the reduction of depth of cut and increase of workpiece speed will help to reduce the heat generation. 

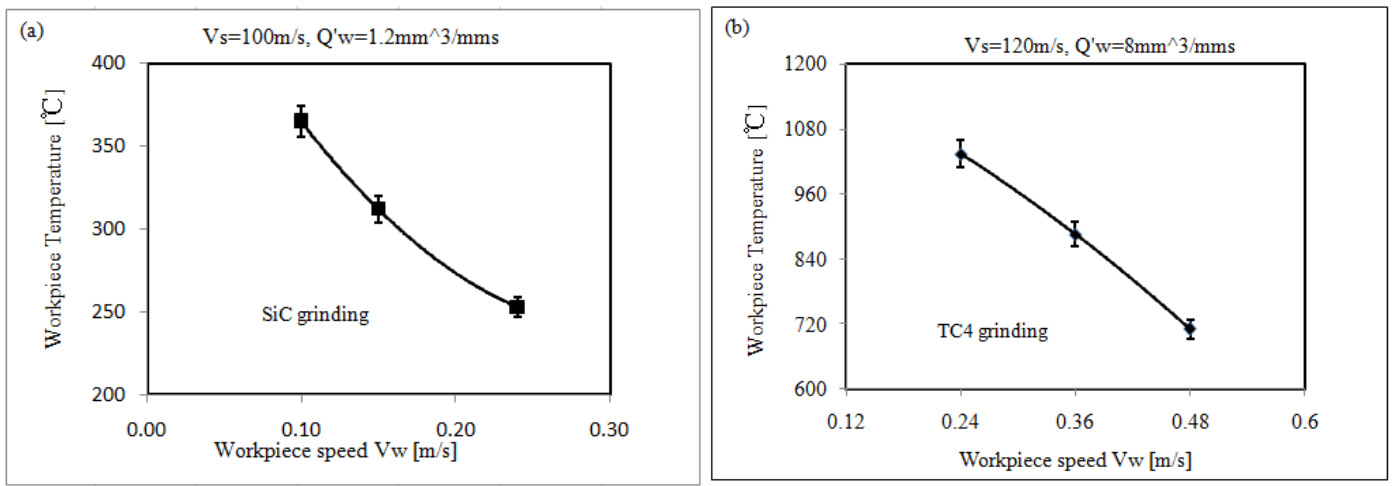

Figure5. Fast shallow plunge grinding for a lower temperature

\section{Conclusions}

This paper has discussed the different temperature characteristics in high speed grinding of typical brittle materials and ceramics in detail. The results show that the grinding temperature for different materials differs a lot. For the $\mathrm{SiC}$, when the wheel speed is below $80 \mathrm{~m} / \mathrm{s}$, the temperature rises and when it is higher than $80 \mathrm{~m} / \mathrm{s}$ the temperature goes down. However, the TC4 shows a liner increase all the way with the increase of wheel speed. This is more because that $\mathrm{SiC}$ has a higher heat dissipation rate and stronger deformation resistance. Moreover, coolants help to reduce about $30 \%$ of grinding temperature for $\mathrm{SiC}$ grinding. In order to achieve a higher material removal rate, the increase of the worktable speed brings out a lower temperature for the increase of heat transfer rate into the air. Finally, it is suggested that a fast shallow grinding helps to reduce both of the SiC and TC4 to suppressing a higher temperature.

\section{Acknowledgements}

This work is sponsored by the National Natural Science Foundation (51675096), National Major Projects (2013ZX04001-141), the Innovation Funds of Donghua University (CUSF-DH-D-2015100) and Morris M. Bryan Jr. Professorship for Advanced Manufacturing Systems. The authors hope to record their special thanks to the generous supports.

\section{References}

1. S. Agarwal, P. Venkateswara Rao, Int. J. Mach. Tool. Manu. 50 1077-1087(2010)

2. C.J. Wu, B.Z Li, J.Z. Pang, S. Y. Liang, J. Adv. Mech. Des. Syst. Manu. Vol.10, No.2(2016)

3. C.J. Wu, B.Z. Li, S.Y. Liang, Proce. Instit. Mech. Eng. B-J. Eng. Manu. Vol.230(8)1372$1380(2016)$

4. C.J. Wu, B.Z. Li, Y. Liu, J.Z. Pang, S. Y. Liang, Int. J. Adv. Manuf. Tech. (to be published)

5. Y. Q. Zhu, T. Sekine, T. Kobayashi, E. Takazawa, J. Mater. Sci. 33, 5883- 5890(1998)

6. G.A. Schneider, [D]. Stuttgart: Universität Stuttgart (1989)

7. C.H. Zhan, W.Y. Yang, Int. J. Mech. Sci. Volume 119, Pages 125-143(2016)

8. H. Huang, K. Eng. Mater. Vol. 404, pp 11-22(2009)

9. C Salomon, Verfahren zur Bearbeitung von Metallen oder bei einer Bearbeitung durch schneidende Werkzeuge sich ähnlich verhaltenden Werkstoffen: DE, (1931)

10. H. Schultz, Proc. Win. Ann. Meet. ASME, New Orleans, , pp. 241-244( 1984)

11. D. O’Sullivan, M. Cotterell, J. Mater. Process. Tech. 118 301-308(2001)

12. M. Hitchiner, Ind. Diam. Assoc. Amer.(2003)

13. C.J. Wu, B.Z. Li, S.Y. Liang, J.G Yang, Adv. Mater. Res.ols. 1120-1121, pp. 1251-1256(2015) 
14. A.D. Batako, W.B. Rowe, M.N. Morgan, Int. J. Mach. Tool. Manu.45, 1231-1245(2005)

15. T. Kuriyagawa, K. Syoji, H. Ohshita, J. Mater. Process. Tech. 136,39-47 (2003)

16. A. Lefebvre, P. Vieville, P. Lipinski, C. Lescalier, Int. J. Mach. Tool. Manu. 46(14), pp. 17161726. (2006)

17. D.H. Zhu, B.Z. Li, J.Z. Pang, J.G. Yang, D. Zhang. ASME Int. Mech. Eng. Cong. Exp. Proceed., 9: 2035-2041( 2010)

18. B.Z. Li, D.Z. Zhu, J.Z. Pang, J.G. Yang, Int. J. Adv. Manu. Tech. 54(9), pp. 931-940(2011)

19. J.M. Longbottom, J.D. Lanham, Int. J. Mach. Tool. Manu. Vol. 46, 14, pp1740-1747. (2006) 